\title{
Cedecea davisae
}

National Cancer Institute

\section{Source}

National Cancer Institute. Cedecea davisae. NCI Thesaurus. Code C86246.

A species of facultatively anaerobic, Gram-negative, bacilli assigned to the phylum

Proteobacteria. This species is motile using 5 to 9 flagella, non-spore forming, catalase positive, oxidase negative, lipase positive, indole negative, ornithine decarboxylase positive, ferments sucrose, reduces nitrate, does not produce hydrogen sulfide, and only weakly hydrolyzes esculin. C. davisae is pathogenic to immunocompromised patients causing super infections and nosocomially acquired bacteremia. 